J Neurosurg 101:895-903, 2004

\title{
Music, musicians, and the brain: an exploration of musical genius
}

\author{
The 2004 presidential address
}

\author{
A. John Popp, M.D. \\ Neurosciences Institute, Albany Medical Center, Albany, New York
}

\begin{abstract}
$\checkmark$ The concept of musical genius used to frame a discussion of the "art" practiced by neurosurgeons is the focus of the 2004 Presidential Address to the American Association of Neurological Surgeons (AANS). The musical genius, in contrast to the musically talented individual, is profiled and placed in the pantheon of those who have demonstrated extraordinary creativity. Observations and speculations about the specialization and elaboration of brain structures in musicians evolve into a discussion of artificial intelligence as a foil to what constitutes the essence of humanity. Taking an inductive approach, the author juxtaposes the conclusion about "music, musicians, and the brain" with the theme of the 2004 annual meeting of the AANS, "Advancing Patient Care Through Technology and Creativity," to elaborate on the characteristics of the consummate neurosurgeon. (Note: Musical vignettes used in the address can be found in the accompanying article posted on Neurosurgical Focus http://www.aans.org/education/journal/neurosurgical).
\end{abstract}

KEY WORDS • music • musician • brain • neurosurgery • creativity

I would like to thank Bob Ratcheson for his entertaining introduction. I can assure you all that the AANS will be in capable hands with Bob Ratcheson as the next president.

While viewing those images of my life contained in Bob's introduction, I was reminded of individuals, many of whom are here today, who have been supportive during my term this past year as president of the AANS. Others not mentioned in the introduction who have aided me considerably, in addition to the AANS staff, Executive Committee, and Board of Directors, include the residents, attending neurosurgeons, and office staff of the Neurosciences Institute at Albany Medical Center, who kept our busy clinical practice and academic endeavors robust during my term as president. I also wish to extend my appreciation to those in $\mathrm{Al}$ bany, who allowed latitude in my responsibilities, making it possible for me to continue a busy clinical practice and an equally time-intensive leadership role in Albany at the same time I was leading the AANS. These individuals are Jim Barba, Chief Executive Officer of Albany Medical Center, Vince Verdile, Dean of Albany Medical College, Steve Frisch, Hospital Director of Albany Medical Center Hospital, and Gary Kochem, Chief Operating Officer of Albany Medical Center. I would like to thank Dr. Arthur Schilp, always the consummate neurosurgeon and the man who inspired me to enter neurosurgery, and also Sunny Stall, President of the Schaffer Foundation, which endowed my chair in the Department of Surgery, and who even more signifi-

\footnotetext{
Abbreviations used in this paper: AANS = American Association of Neurological Surgeons; MR = magnetic resonance; PET = positron emission tomography.
}

cantly became my great friend and confidant. Most importantly, I want to take this opportunity to publicly express my appreciation to my wife, Margaret Vosburgh, who so often is my inspiration and who always is my better half.

\section{The Theme of the 2004 Annual Meeting of the AANS}

The theme of the 2004 Annual Meeting, "Advancing Patient Care Through Technology and Creativity," focuses our attention on the concordance between the science of neurosurgery and the art necessary to practice it with mastery in the service of our patients. At the core of our art resides our respect for our patients and a profound interest and curiosity regarding the brain - the intriguing organ that is the focus of our profession-about which we have learned so much, yet about which so much remains a mystery.

\section{Music, Musicians, and the Brain}

My talk today, "Music, Musicians, and the Brain," explores one particular mystery and a lifelong fascination of mine, the phenomenon that we call music. I plan to share with you some observations and speculations about musicians and brain function related to music. I specifically will focus on certain markers for recognizing musical genius; some of the information we have about how the brain processes musical information; and, ultimately, how we can use this information inductively to inform us as neurosurgeons in our roles as healers, educators, and scientists.

I begin with a brief overview of my own education in 


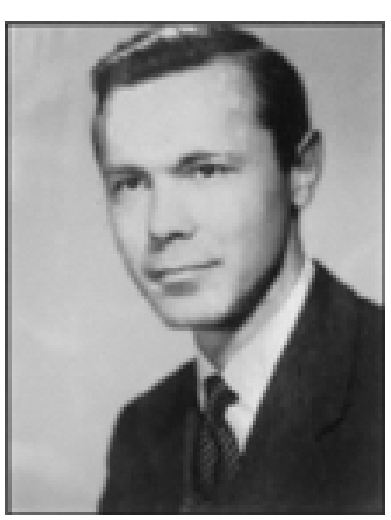

FIG. 1. Photograph showing Dr. Richard A. Lende [1924-1973]: a Penfield and Woolsey trainee. From the author's personal collection.

neurosurgery and music. Among my teachers in neurosurgery was Richard Lende (Fig. 1), who trained with two renowned investigators in the field of cerebrocortical organization, Wilder Penfield at the Montreal Neurological Institute and Clinton Woolsey at the University of Wisconsin. My education in music was guided by individuals who trained at the Eastman School of Music, Julliard, and the Paris Conservatoire. Those of you with an interest in either cerebrocortical organization or music will recognize these individuals and institutions as having made considerable contributions to their respective fields.

One must exercise care when claiming to be a pupil of one teacher or another, as if the mere association lends credibility to an individual's opinions and talents. I am reminded of the story, perhaps apocryphal, of an organ grinder who performed selections of Giuseppe Verdi's opera "Il Trovatore" beneath the composer's window. Verdi admonished the performer for playing too loudly. When the organ grinder returned the following day his instrument displayed a sign with the statement: "Verdi's pupil."3

When people ask me what I do musically, I usually say that I "play the piano;" however, I read in "Ripley's Believe It or Not" that Shirley Mae Ross of Rockville, Maryland, taught her pet schnauzer to play the piano. Based on that observation, I question the advisability of proclaiming that I am a pianist. If pressed on the point, however, I would characterize my ability, and I do so confidently, as falling somewhere between that exhibited by the phenomenal pianist Vladimir Horowitz in his prime and Shirley Mae Ross' pet schnauzer.

[Musical Vignette No. 1. Chopin F: Ballade No. 4 in F

Minor, Op. 52, performed in concert by Vladimir Horowitz at the Metropolitan Opera House. Track 7, 00:00-00:25 (Disk No. 9026-63314-2). BMG Entertainment. Recorded 1981, reissued 1999. Compact disk.]

I recall the first time that I thought about musical genius. I was 12 years old and studying the Chopin F-minor Ballade (Fig. 2). ${ }^{12}$ In my opinion this work contains some of the most sublimely elegant melodies and substantial technical difficulties found in the piano literature. I remember that for Christmas that year I received a recording of the Ballade played by Horowitz. Never having heard another pianist perform the work, I eagerly placed the phonograph needle

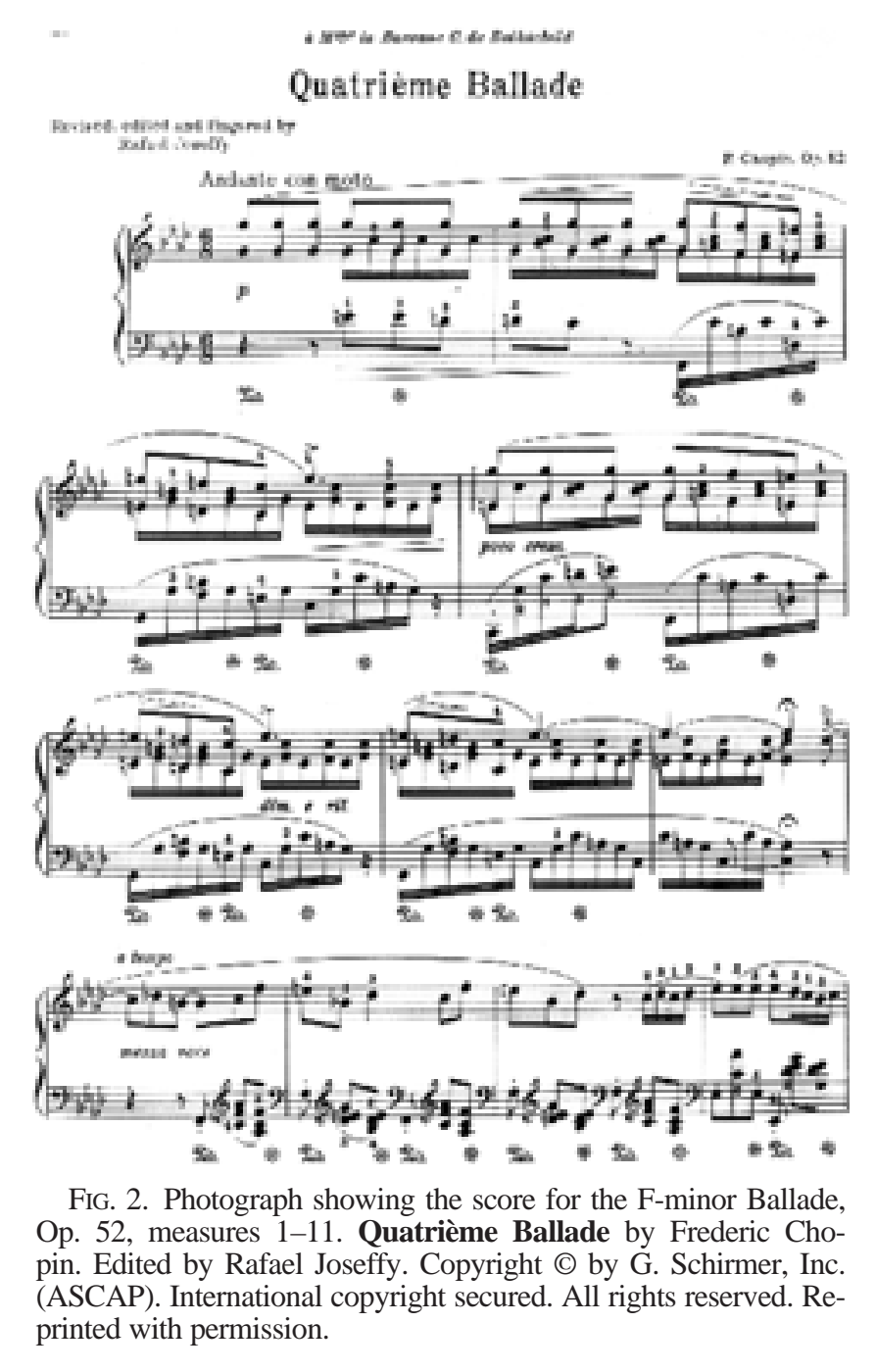

on the record. The revelation was instantaneous, painful, and one that lasts to this day. In a single moment, I recognized that here was something distinctly different-wonderful in its execution but incomparable in its grandeur and panache. In the next moment I contemplated my future occupational options and dropped music from the list. Since that event, however, I have been curious about how the brain processes the information that translates into the wonders that emanate from the minds and hands of these rare musical geniuses.

I pose for you two rhetorical questions. "What constitutes musical genius?"- that is, how is it defined and how is it manifested-and "How does the brain of the gifted musician differ from that of the average individual?" These questions are complex in their implications, so much so that important information bearing on the subject matter must be eliminated from this discussion because of time constraints.

\section{How is Musical Genius Defined and Manifested?}

What constitutes musical genius? To consider this question, let me reflect for a moment on a few of the external manifestations exhibited by the gifted musician, in an attempt to provide a sense of the type of individual we are analyzing - a psychological profile if you will. 


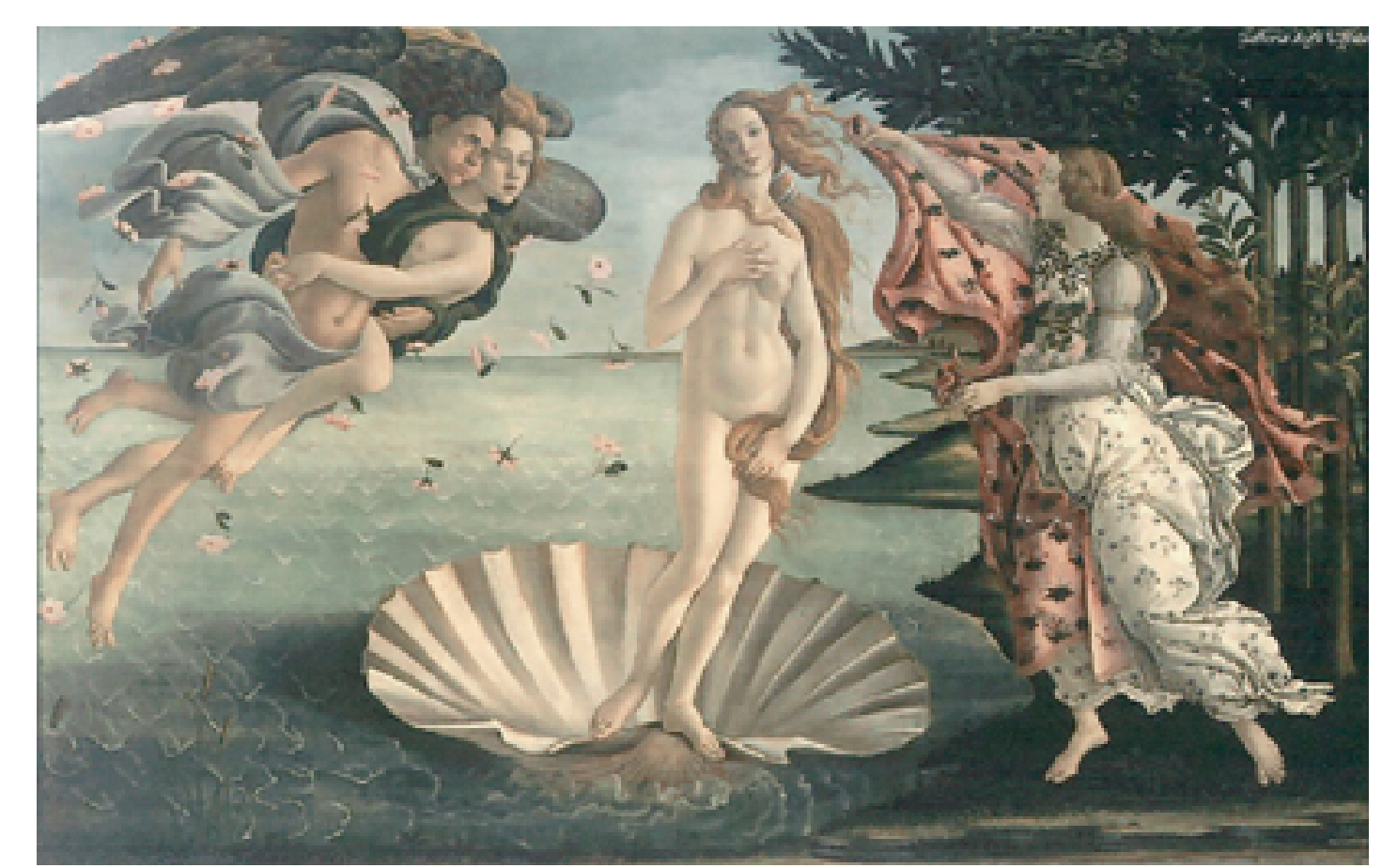

FIG. 3. "The Birth of Venus" by Sandro Botticelli, ca. 1485, Uffizi Gallery.

There is great likelihood that virtually everyone at this meeting falls between two extremes of musical ability: at one end is the musical genius of Mozart, who could pick out chords on the harpsichord at the age of 3 years, and at the other extreme is General Ulysses S. Grant, who used to say, "I know only two tunes. One of them is Yankee Doodle. The other isn't." ${ }^{3}$ In fact, individuals who are "tone deaf" constitute approximately $5 \%$ of the population. Unlike speech, however, music is thought by many not to be a biological necessity, which may explain the greater variation observed in the general population in the ability to compose and perform music. Whereas "talent" is generally recognized as a natural or acquired ability of superior quality, "genius" is closely linked to transcendent creative powers. These powers are not the result of a compulsive work ethic or a superior education, but rather spring forth unbidden from mysterious origins, mature like the goddess in Botticelli's painting, "The Birth of Venus" (Fig. 3).

A better understanding of musical genius calls for a brief digression into the very concept of genius, which has been the subject of numerous discourses and investigations, particularly in the 19th and 20th centuries. In Genius: the History of an Idea ${ }^{11}$ Penelope Murray explores genius as a concept that has changed considerably from ancient to present times.

The impact of the creative element in "genius" is elusive, particularly as it applies to the arts. If Sir Isaac Newton had not formulated the theory of colors during his Anni Mirabili (the miraculous years 1665 and 1666), it is likely that someone else would have eventually done so. If Beethoven had not written his "Eroica" symphony or Chopin his Ballades, however, it is doubtful that another would have stepped forward to create these particular works.

The modern use of the term genius derives from the Latin word ingenuus, which implies innate ability. In classical times divine inspiration was thought to beget genius, a concept that gave way to Renaissance Humanism, in which genius was viewed as a natural endowment. This evolution in the concept of the source of genius brought with it certain dialectical problems such as the following. What defines musical genius? Is genius part of a continuum of the talent spectrum or a separate locus altogether? To illustrate the latter, in Fig. 4, the white node signifies at what point a genius of Mozart's magnitude might fall in each of these two scenarios.

As Murray describes, during the Romantic era the concept of genius conjured an individual with transcendent powers struggling with an inhospitable world-a world not ready for the creative forces and artistic advances represented by the genius' labor. Doktor Faustus, in Ferrucio

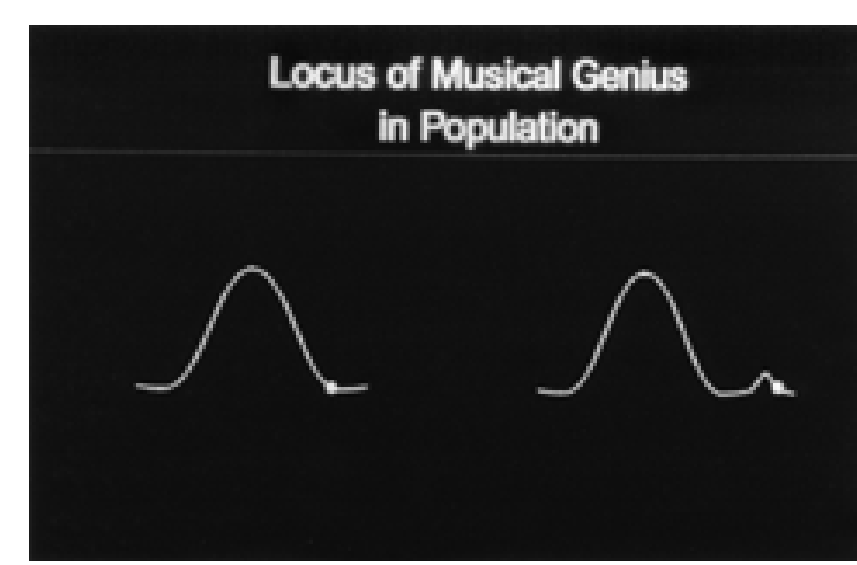

FIG. 4. Models of the locus of genius in the general population. Nodal markings represent the locations of musical talent for a genius of Mozart's caliber in two theoretical population distributions. 
Busoni's opera by that name, perhaps captured the essence of this struggle best when he proclaims, "Give me Genius with all its pains." 11

In an interesting study of the mental traits of geniuses published in 1926, $\operatorname{Cox}^{1}$ found that only one of 11 musicians studied demonstrated outstanding abilities in other fields. This was the composer Felix Mendelssohn from the Romantic era, whose intelligence quotient was near the top among musicians. Mendelssohn, was proficient in drawing as well as in Greek and Latin. He also was born to a family with considerable cultural and financial wealth, however, and thus had access to a wide range of activities and resources. This example aside, most musicians predominately do what they do best-compose and perform music. Perhaps this one dimensionality is the price of specialization, given the long hours that must be devoted to music if the individual with musical talent is to develop fully.

Gardner ${ }^{4}$ has noted,

... there is a "tyranny of talent" which tends to force the narrowing of anyone with extraordinary high ability in a specific line. Once the talent is developed it is often so highly

rewarded that the individual is apt to neglect [or not discover]

his other talents; and society abets him in this neglect.

Much has been made of the one dimensionality, idiosyncrasies, and potential for mental illness evidenced by geniuses, and musical geniuses are no exception. The Roman playwright Seneca wrote, "there is no great genius without a touch of madness." Nevertheless, despite examples of mental illness in famous composers, a high level of cognitive functioning during composition and performance appears to be essential to the creative process in music.

Because of their all-consuming interests in music, however, musicians - and composers in particular-often have been labeled eccentric and their interpersonal relationships have been reported to be poor. In his collection of musical anecdotes David Ewan ${ }^{3}$ relates the following story about Gioacchino Rossini, perhaps best known today for his opera "The Barber of Seville." Apparently, Rossini's sarcasm could cut as sharply as a barber's razor. When a young composer offered to play two original works for Rossini, the great man only listened to the first and said quickly, "I like the other one better."

This psychological profile would be incomplete without a discussion of the positive features that seem to mark the musically gifted. To name only the most obvious, I include precocity, preeminent musical faculties including notational and sonic memory, and transcendent compositional and performance abilities.

I begin with precocity, the hallmark of the musical genius. Musical aptitude invariably declares its presence in the first decade of life; in fact there has never been a virtuoso musician who was not a child prodigy. Consider Mozart, who at 5 years of age had already composed his first two works and at 8 years of age, his first symphony: Mozart was believed to have played both organ and violin without taking a single lesson.

The second mark of the gifted musician is musical memory. In a gifted musician, musical memory is profound both in completeness and duration. One of Mozart's most celebrated musical exploits occurred in Rome when he was only 14 years old. During Holy Week every year, Gregorio Allegri's "Miserere" was sung at the Sistine Chapel.

[Musical Vignette No. 2. Allegri G: Allegri: Miserere, per- formed by Stephen Cloebury and the Choir of Westminster

Cathedral, Track 6, 00:00-00:20 (Disk No. 28941-00052). The Decca Record Co., Ltd., London, 410005-2. Compact disk.]

The complete "Miserere," lasting 12 minutes, is complex and polyphonic; it contains nine parts for two choirs and is elaborately ornamented. The manuscript was considered a Vatican treasure and was jealously guarded and unpublished. Yet, young Mozart heard the work only once and reconstructed the score from memory. ${ }^{1,3}$

A third sign of musical genius is a rare and electrifying capability for composition and performance-one that causes excitement for audiences and envy in contemporary rivals.

[Musical Vignette No. 3. Paganini N, Moto Perpetuo, Op. 11, performed by Jascha Heifetz. Disk 1, Track 12,

00:00-00:30 (Disk No. 7863-50942-2). BMG Music, reissued 1975. Compact disk.]

In the fall of 1917, Carnegie Hall was packed with attentive musicians for the sensational debut of the 16-yearold violinist, Jascha Heifetz. It was a warm evening and Leopold Godowsky, a prominent pianist, shared a box with Misha Ellman, an equally prominent violinist. Mopping his brow, Ellman complained, "It's hot in here." Godowsky, known for his great wit, quickly responded, "Not for pianists!"16

There are numerous other examples of superlative technical ability in composition and performance that inspire a sense of awe in the rest of us who are less gifted.

Perhaps what best characterizes the musical genius is an emotion evoked in us called by Koestler' the "oceanic feeling"- a participation in the mystery of the infinite. I read Richard Westfall's biography of Sir Isaac Newton, in which Westfall expressed the concept of genius in the following manner.

The more I have studied him, the more [Isaac] Newton has receded from me. It has been my privilege at various times to know a number of brilliant men, men whom I acknowledge without hesitation to be my intellectual superiors. I have never, however, met one against whom I was unwilling to measure myself, so that it seemed reasonable to say that I was half as able as the person in question, or a third or fourth, but in every case a finite fraction. The end result of my study of Newton has served to convince me that with him there is no measure. He has become for me wholly other, one of the tiny handful of supreme geniuses who have shaped the categories of human intellect, a man not finally reducible to the criteria by which we comprehend our fellow beings. ${ }^{17}$

\section{Evidence for the Special Functioning and Anatomy of the Musician's Brain}

We now move from the external manifestations of musical genius to an exploration of how the physical brain of the genius differs from that of an average person. Useful clues can be found in the fields of neuropsychology, neuroanatomy, and neuropathology.

I will not delve deeply into the neuropsychological aspect of investigations; however, a psychological assessment of musical ability indicates that the mind of the musician may be "rule governed." We are all subject to rule-governed behavior of some sort, but perhaps the mind of the musician is better developed in this sphere. In his book Gödel, Escher, Bach: An Eternal Golden Braid, Douglas Hofstadter opines, "Perhaps the musician's brain is programmed with 


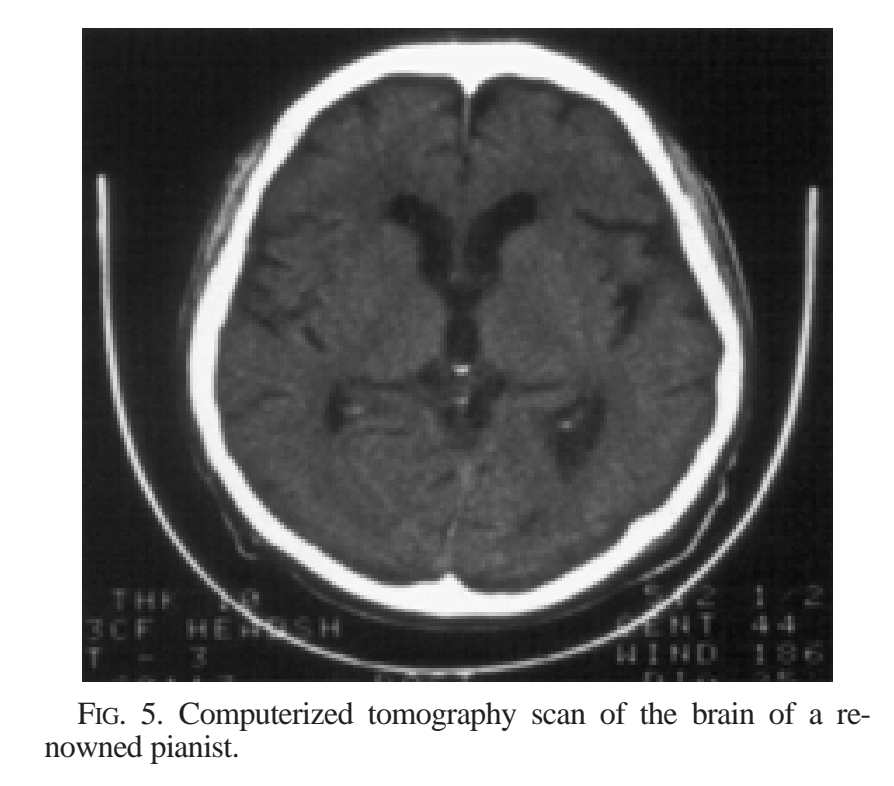

a better set of rules which do not allow their brains to make mistakes in pitch, tone, timbre or all the other elements of musical ability." 5 This theory implies that the brain of a musician is "hard wired," with an emphasis on particular circuits that facilitate musical information.

Others believe genius is actually "discipline disguised." Violinist Isaac Stern reportedly believed that exalted music making only could be accomplished by understanding what is possible - a state attained by acquiring enormous discipline, which when achieved freed the imagination.

Musicians themselves seem to have little understanding of their talent. Bach provided a simple explanation for his exceptional ability as an organist: “. . . there is nothing very wonderful about it. You have only to touch the right key at the right time, and the instrument does the rest." 3

To those of us who are not so blessed, great musicians appear to be born with an innate ability that most of us can never hope to match. Intuitively, musicians must have special anatomical features of the brain that enable them to excel in music at levels beyond the rest of us, but what is the evidence for this and how does this "facilitatory" anatomy for music have any bearing on the broader picture of brain function?

Based on studies of patients, the evidence for the specialization of musicians' brains can be viewed from several perspectives: anatomical studies, clinical studies in which positive and negative musical phenomena are described, and physiological imaging studies.

Regarding brain anatomy, there have been reports on autopsy assessments of musicians' brains, including one in which the brain of Hans von Bulow, a notable 19th century pianist and conductor, is described. Von Bulow's brain was found to have enlargement of the supramarginalis gyrus and middle and posterior thirds of the superior temporal gyrus. ${ }^{10}$ Until recently, however, most anatomists have not drawn significant conclusions about musical ability related to the appearance or size of specific areas of the brain because of the degree of variability in brain anatomy. Figure 5 displays a computerized tomography scan obtained in a 70-year-old patient in which the findings are normal in every way ex-

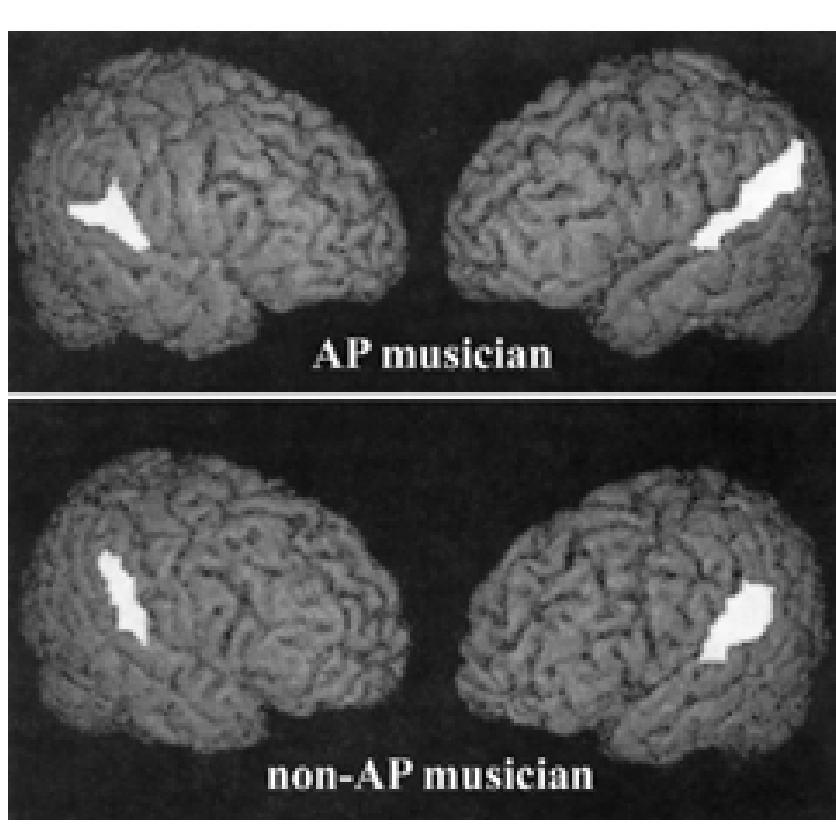

FIG. 6. Comparison images of the left planum temporale in musicians with absolute pitch (AP) and without absolute pitch. Reprinted with permission from Schlaug G: The brain of musicians: a model for functional and structural adaptation. Ann NY acad Sci, Vol 930, The Biological Foundations of Music, color Fig. 6, p 293 (c) 2001 New York Academy of Sciences, U.S.A.

cept for mild cortical atrophy. There is no distinguishing anatomical feature in the scan to suggest that this is the brain of one of the most famous concert pianists in history.

More recently MR morphometric studies have demonstrated that certain portions of the brain, such as the corpus callosum, motor cortex, and cerebellum, differ between musical professionals and musically unsophisticated persons. These studies can be explained by either innate developmental differences or changes induced by plasticity with hypertrophy of certain areas in response to the rigorous practice necessary for performance. ${ }^{15}$ Furthermore, as shown by Fig. 6, MR morphometry has identified asymmetry of the left planum temporale in musicians with absolute pitch compared with musicians without absolute pitch. ${ }^{15}$

A considerable number of clinical studies have focused on musical phenomena in musicians and nonmusicians. In these studies both positive and negative phenomena have been investigated. "Positive phenomena" are the components of musical experience that are expressed when the brain is stimulated either by an epileptogenic event or during brain mapping. "Negative phenomena" occur as a result of congenital disorders, surgical resections, or brain lesions such as stroke.

Positive phenomena, found during stimulation of the primary auditory receptive area of the cerebral cortex in the awake patient undergoing surgery for epilepsy, invariably are described as a monotonous sound devoid of complicated qualities. These uncomplicated tones obviously do not represent music, but potentially a component of the musical experience. More elaborate auditory phenomena occur when the site of stimulation moves away from the primary auditory receptive area. In Penfield's text, cases are de- 


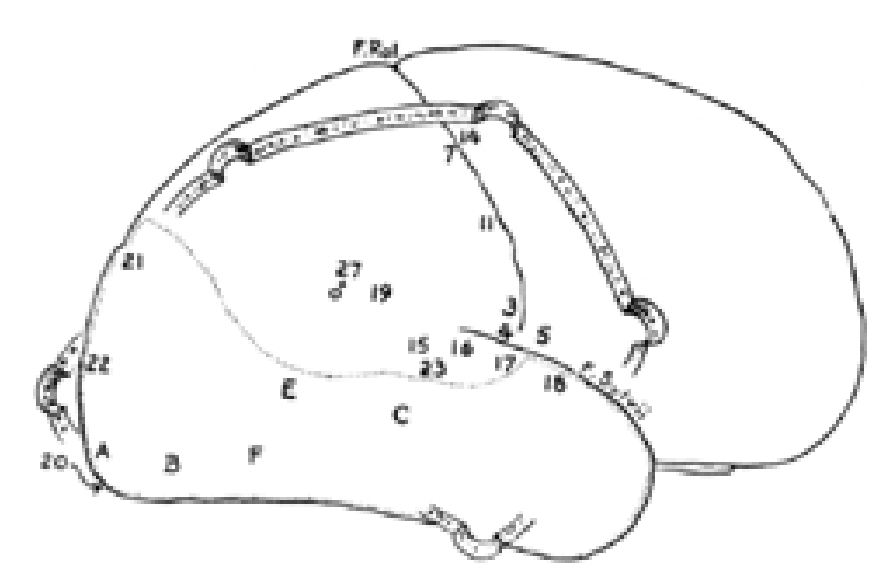

FIG. 7. Penfield Case A.Bra: Surgeon's Drawing. Reprinted from Penfield W, Jasper H. Epilepsy and the Functional Anatomy of the Human Brain. Boston: Little Brown and Co., 1954

scribed in which extensive areas of the cortex were stimulated. ${ }^{14}$ Figure 7 shows the operative diagram of a woman who had experienced seizures 9 months earlier. During intraoperative stimulation at Site 7 , which is in the primary sensorimotor cortex, the traditional site of cerebral cortical sensory representation for the hand, the patient reported numbness in the left thumb and the index finger. During stimulation at Site 15 , which is near the primary auditory cortex, the patient claimed, "I hear singing;" when this area was stimulated again, she stated, "Yes, it is "White Christmas'. . . There is an orchestra, too . . . yes, a choir."14
In contrast to positive phenomena, negative phenomena are represented by a loss of musical function due to congenital lesions such as congenital amusia, described earlier for Ulysses Grant, or acquired disorders such as those caused by strokes or as a result of brain extirpation during brain tumor excision or epilepsy surgery.

Two examples of negative phenomena will suffice. Luria and colleagues ${ }^{9}$ studied the Russian composer Vissarion Shebalin, who suffered a stroke of the left side of the brain that produced significant difficulty with speech. Shebalin nonetheless continued to compose. Fellow composer Dimitri Shostakovich called Shebalin's Fifth Symphony, composed after the stroke, "a brilliant creative work, filled with highest emotions, optimistic, and full of life. This symphony composed during his illness is a creation of a great master." In the second example, Critchley ${ }^{2}$ described a composer who experienced speech difficulty and inability to compose due to a benign tumor of the brain. After removal of the tumor, both speech and musical creativity rapidly returned. Based on these two isolated observations we may correctly conclude that in some musically talented individuals, speech and musical creativity are proximate in the cerebral cortex, and in others they are not.

Over the past two decades great progress has been made in understanding the brain processes associated with musical function. These advances have been made possible by new imaging modalities such as PET scanning, functional MR imaging, and magnetoencephalography.

I will only elaborate on one of these studies, which exemplifies the extensive work being done in this area. ${ }^{13}$

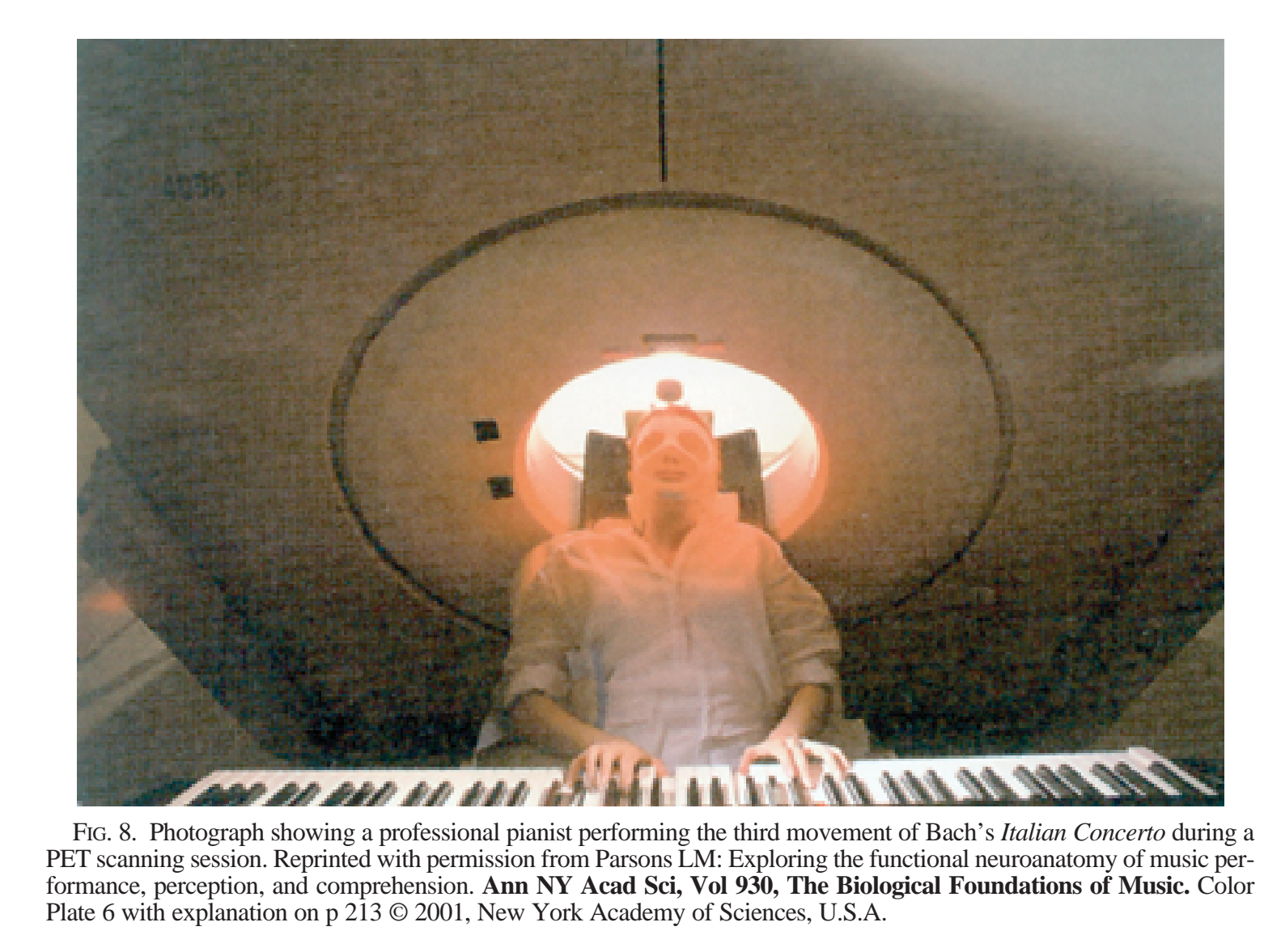




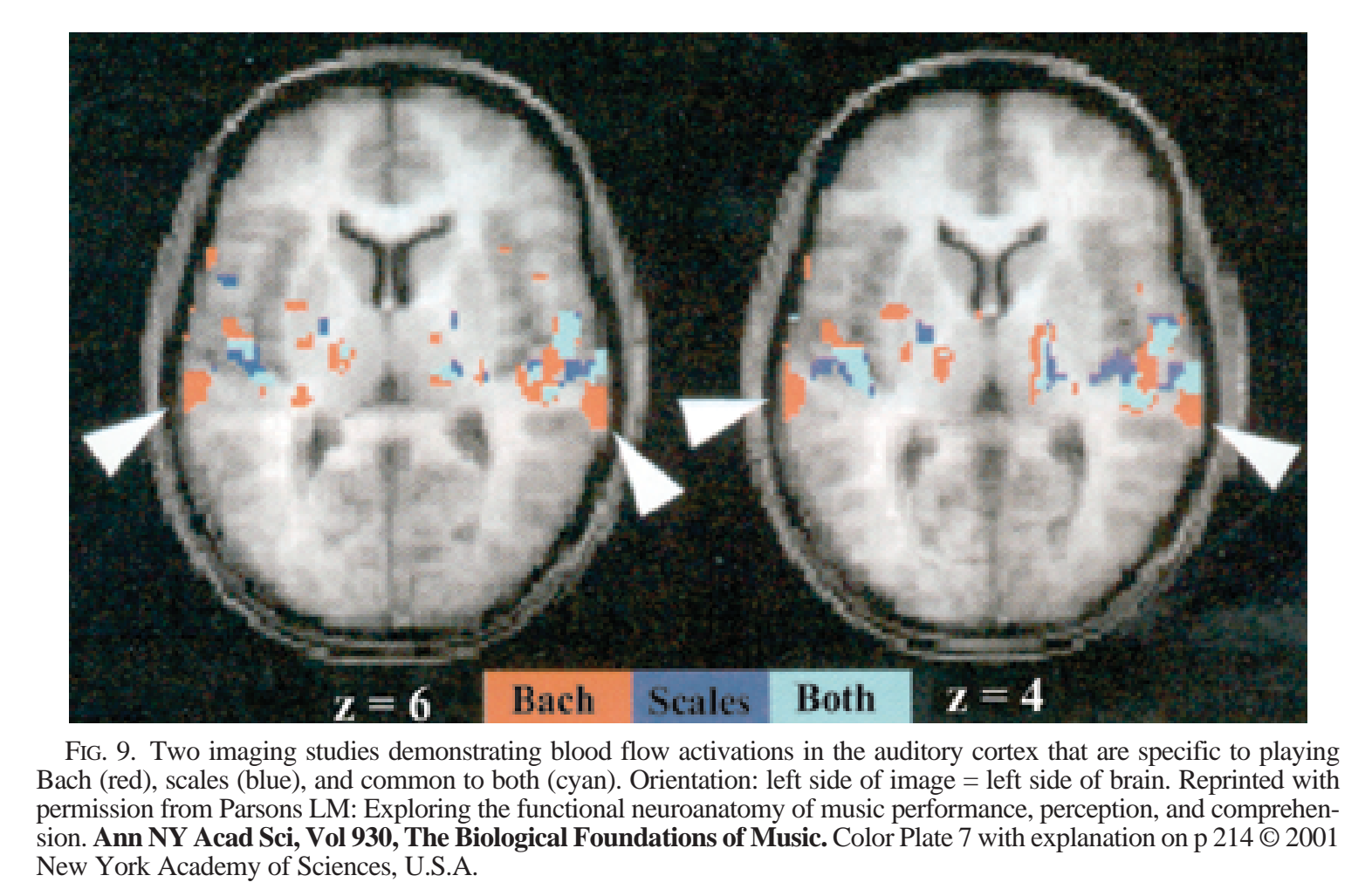

Eight professional pianists underwent PET scanning, during which they were asked to perform two contrasting tasks from memory: the third movement of Bach's Italian Concerto and scales using both hands (Fig. 8). The goal of this study according to the investigator was "to reveal the outline of brain areas that were specifically involved in the cognitive, perceptual and emotional representation and performance of effective, strongly engaging music...."

Figure 9 displays only a single slice from the sequence. The red areas represent sites activated only by Bach, the blue areas sites activated solely by playing scales, and the cyan areas sites of overlap between performing Bach and playing scales. This study demonstrates that the neural systems underlying music are widely distributed in the cerebral and cerebellar hemispheres and that distinct neural circuits process different aspects of music.

\section{Inductive Insights: Musical Genius and Neurosurgery}

Will the research on music and the brain that I have partially presented today ultimately lead to the scientist's analysis of the complex circuitry involved in and exhibited by musical geniuses, thus allowing us to create a machine that is an artist? Douglas Hofstadter, whom I referenced earlier, provides insight into this subject in his book Gödel, Escher, Bach, ${ }^{5}$ when he attempts to answer the question, "Will a computer program ever write beautiful music?" Hofstadter's answer is, "Yes, but not soon. Music is a language of emotions, and until programs have emotions as complex as ours there is no way a program will write anything beautiful." Hofstadter calls the idea that a machine could create music the likes of Chopin or Bach a "grotesque and shame- ful estimation of the depth of the human spirit." He postulates that "a 'program' which could produce music as they did would have to wander around the world on its own, fighting its way through the maze of life and feeling every moment of it."

In the area of artificial intelligence there have been predictions of computers that are conscious. Raymond Kurzweil, a futurist and inventor of pattern recognition technology, predicts that in the 2020s computer intelligence constructed by reverse engineering principles will exceed human intelligence. He additionally predicts that humans and computers will merge via nanoscale neural implants in the brains of humans. ${ }^{7,8}$

Whether technology ultimately will be able to diagnose the essence of consciousness and cognitive function, thus unlocking the secrets concerning music, musicians, and the brain, remains an unanswered question. Nevertheless, this discussion of technology returns us to the theme of our meeting, "Advancing Patient Care Through Technology and Creativity." Figure 10 offers a visual representation of this theme. In this figure the brain serves as a nexus between creativity represented by Van Gogh's "Starry Night" on the right side and technology represented by the graphic composition on the left - a melding of the essence of what I believe we do as neurosurgeons.

Technology has enhanced our specialty. It has made diagnosis and surgery more accurate, safer, and faster, resulting in better outcomes. We are indebted to industry, represented en force in our exhibit hall, for help in developing and bringing to the market the technology that allows these substantial improvements in patient care. We also are indebted to those neurosurgeons and scientists whose creativity has stimulated the development of these technologies.

I tell my residents that no two patients have the same 


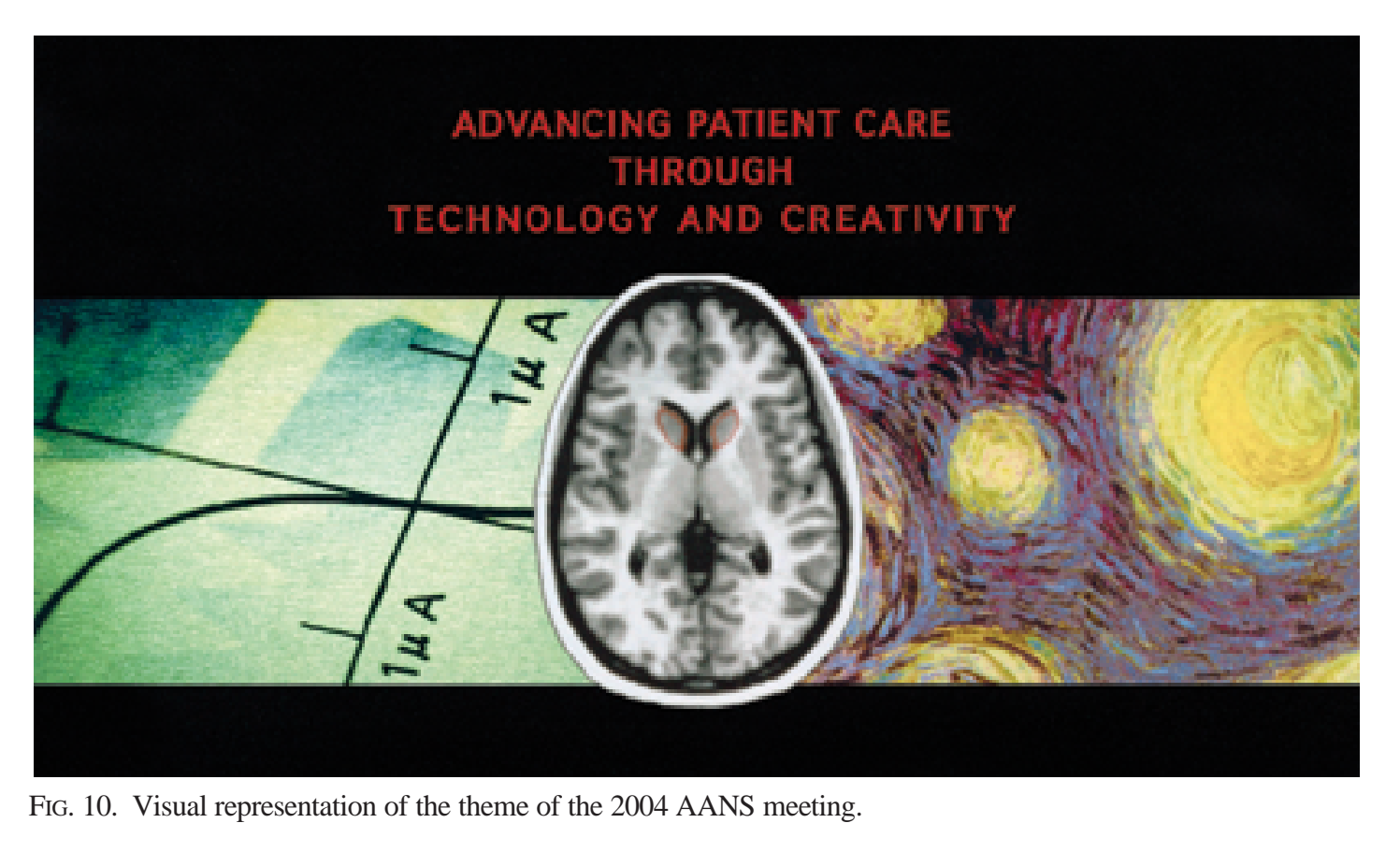

anatomy, physiology, or pathology, and that although technology, knowledge, and experience help minimize the impact of these differences on treatment planning, I believe that we as physicians recognize that excellence in neurosurgery still requires a leap of creativity when quantifiable attributes do not suffice.

At the focus of our use of technology and creativity, similar to the brain in Fig. 10, is the patient - each one uniquea uniqueness perhaps best appreciated by the flamboyant example of the musical genius. It is this unique confluence of technology and creativity that embodies the noble concept of the consummate neurosurgeon.

What we do as neurosurgeons-the art of neurosurgery_can be elaborately dissected, but not fully explained. Likewise, I fear that the scientist's quest to explain musical genius is doomed to failure. It appears that it is a task not dissimilar to quantifying and measuring the human spirit itself. It seems to me that there are times when we must set aside our instruments of inquiry and simply enjoy the genius embodied in the music of the masters. Let us do that for a moment now.

[Musical Vignette No. 4. Chopin F: Ballade No. 4 in F

Minor, Op. 52, performed by Vladimir Horowitz, Track 6,

08:03-09:05 (Disk No. 7863-57752-2). BMG Music RCA

Corp. 7752-2-rG. Recorded 1972, reissued 1990. Compact disk.]

This is the finale of the F-minor Ballade by Frederic Chopin played by Vladimir Horowitz- the same performer and the same composition that began my thoughts about musical genius more than four decades ago. You may prefer the interpretation of this work by another pianist or you may enjoy other composers more than Chopin, but I think that none of you will deny the genius of either the performer or composer or, on reflection, the miracle of the brain structure that produced what you have just heard.

To this day music continually provides me with a sense of anticipation, excitement, inspiration, and even melan- choly_conflicting emotions that are not unfamiliar to the neurosurgeon. Pondering music, musicians, and the brain reminds me that the exploration of genius has broader implications for neurosurgery and for humanity as a whole. On cursory reflection it becomes apparent that the miracle of the mind is not solely a gift to the select few whom we have discussed today, but a gift that each of us nurtured during our education and subsequent careers and, if we broaden the concept, a quality that I believe we must recognize and value in our patients. I hope by exploring music, musicians, and the brain today that I have imparted the sense of wonderment and near reverence that I feel for the miracle of the mind-a level of appreciation that seems to me to be elemental to delivering the most compassionate and best quality of care to our patients.

\section{Acknowledgment}

A. John Popp, M.D., Henry and Sally Schaffer Chair of Surgery, thanks the Schaffer Foundation for all the support it has given him.

\section{References}

1. Cox, CM, Gillan LO: Genetic Studies of Genius Vol. II: The Early Mental Traits of Three Hundred Geniuses. Stanford, CA: Stanford University Press, 1926, pp 589-594

2. Critchley M: Aphasiology and Other Aspects of Language. London: Edward Arnold, 1970, pp 256-276

3. Ewen D: Listen to the Mocking Words. New York: Arco, 1945, pp 16-141

4. Gardner JW: Excellence: Can We Be Equal and Excellent Too? New York: Harper, 1961, p 60

5. Hofstadter DR: Gödel, Escher, Bach: An Eternal Golden Braid. New York: Basic Books, 1999, pp 676-677

6. Koestler A: The Act of Creation. London: Hutchinson, 1964, p 263 
7. Kurzweil R: The Intelligent Universe. (http://www.KurzweilAI. net/meme/frame.html?main=/articles/art0534.html) [Accessed 29 September 2004]

8. Kurzweil R: We Are Becoming Cyborgs. (http://www. KurzweilAI.net/meme/frame.html?main=/articles/art0449.html) [Accessed 29 September 2004]

9. Luria AR, Tsvetkova LS, Futer DS: Aphasia in a composer. J Neurol Sci 2:288-292, 1965

10. Meyer A: The search for a morphological substrate in the brains of eminent persons including musicians: a historical review, in Critchley M, Hensen RA (eds): Music and the Brain: Studies in the Neurology of Music. Springfield, IL: Charles C Thomas, 1977, pp 255-281

11. Murray P (ed): Genius: The History of an Idea. New York: Basil Blackwell, 1989, pp 1-8

12. Parakilas J: Ballads Without Words: Chopin and the Tradition of the Instrumental Ballade. Portland, OR: Amadeus Press, 1992, pp 31-87
13. Parsons LM: Exploring the functional neuroanatomy of music performance, perception, and comprehension. Ann NY Acad Sci 930:211-231, 2001

14. Penfield W, Jasper H: Epilepsy and the Functional Anatomy of the Human Brain. Boston: Little, Brown \& Company, 1954, pp $511-513$

15. Schlaug G: The brain of musicians: a model for functional and structural adaptation. Ann NY Acad Sci 930:281-299, 2001

16. Schonberg HC: The Glorious Ones: Classical Music's Legendary Performers. New York: Times Books, 1985, pp 374

17. Westfall RS: Never at Rest: A Biography of Isaac Newton. New York: Cambridge University Press, 1980, pp preface

Manuscript received August 18, 2004.

Address reprint requests to: A. John Popp, M.D., Albany Medical Center, 47 New Scotland Avenue, MC61, Albany, New York 12208. email: poppj@mail.amc.edu. 